\title{
Seasonal variation of asthma control, lung function tests and allergic inflammation in relation to vitamin D levels: a prospective annual study
}

\author{
Sehra Birgül Batmaz¹, Tuğba Arıkoğlu², Lülüfer Tamer³, Gülçin Eskandari³, Semanur Kuyucu² \\ 'Department of Pediatric Allergy and Immunology, Tokat State Hospital, Tokat, Turkey \\ 2Department of Pediatric Allergy and Immunology, Faculty of Medicine, Mersin University, Mersin, Turkey \\ ${ }^{3}$ Department of Biochemistry, Faculty of Medicine, Mersin University, Mersin, Turkey
}

Adv Dermatol Allergol 2018; XXXV (1): 99-105

DOI: https://doi.org/10.5114/ada.2017.71421

\begin{abstract}
Introduction: There are scarce data about the role of vitamin D (vitD) in asthma control related to seasons and other confounders.

Aim: To investigate the seasonal relationship between vitD levels and asthma control, lung function tests (LFTs) and cytokines during a 1-year period, among 7-17-year-old asthmatic children.

Material and methods: Thirty patients with asthma with house dust mite monosensitization were evaluated 3 monthly about the previous month's health and vitD related lifestyle factors and asthma control test (ACT), spirometry and bronchial provocation test for a year. Serum vitD, vitD binding protein (VDBP), total IgE levels, absolute eosinophil and Treg counts and cytokine levels were simultaneously measured. The seasonal changes of vitD and other parameters and the relationship between 120 pooled data sets of vitD and major outcomes were evaluated. Results: Mean vitD levels, forced expiratory volume in $1 \mathrm{~s}\left(\mathrm{FEV}_{1} \%\right)$ and $\mathrm{ACT}$ score were lowest in winter and highest in summer. Pooled vitD levels were positively correlated with pooled ACT scores, Treg counts, FEV $\%$ values and VDBP levels and negatively with total immunoglobulin E (IgE) and interleukin-4 (IL-4) levels and bronchodilator response. VitD levels were positively associated with ACT score, and $\mathrm{FEV}_{1} \%$ value and negatively with serum IgE level and bronchodilator response after adjusting for confounders.

Conclusions: This study revealed that asthma control measures, LFTs and IgE levels were significantly related to serum vitD levels, independent from age, body mass index, inhaled corticosteroid use, sun exposure and season among asthmatic children. Vitamin D levels showed a positive correlation with Treg counts and a negative correlation with Th2 type cytokines.
\end{abstract}

Key words: asthma, vitamin D, season, lung function test, cytokines.

\section{Introduction}

Asthma is one of the common chronic diseases, and affects nearly 300 million people worldwide. Asthma may lead to missed school days and lower quality of life [1].

Vitamin D (vitD) is important for organisms, and its effects on the regulation of bone metabolism and calcium homeostasis have been known for a long time. Adequacy of vitD level is assessed by measuring the levels of 25-hydroxy-vitD $(25(\mathrm{OH}) \mathrm{D})$, because of its long half life (i.e. 2-3 weeks), and unlimited production in the liver [2]. Age, body mass index (BMI), skin melanin content, time and duration of daily sunlight exposure, season and latitude are known to affect serum vitD levels [3]. The greater amount of vitD is bound to vitD binding protein (VDBP) and a smaller amount is bound to albumin in the circulation. It is transported to tissues. Then it binds to intracellular vitD receptor (VDR), and the VDR ligand/receptor complex alters the transcription rate of many genes involved in a wide spectrum of biologic responses [4].

After the discovery of VDR on enterocytes, renal tubular cells, pulmonary epithelial cells, dendritic cells, parathyroid cells, keratinocytes, promyelocytes, lymphocytes, colon, pituitary and ovarian cells, studies about the extraskeletal effects of vitD have increased [2].

The relationship between asthma and vitD has become the focus of interest in recent years. Common risk

Address for correspondence: Sehra Birgül Batmaz MD, Department of Pediatric Allergy and Immunology, Tokat State Hospital, Tokat, Turkey, phone: +90 356 2145400, fax: +90 356 2126377, e-mail: drsehra@yahoo.com

Received: 6.09.2016, accepted: 18.12.2016. 
factors for the development of asthma and vitD deficiency have been reported, i.e. western life style, race, and obesity. In particular, the identification of the effects of vitD on the immune system resulted in an increase in the number of studies about vitD and its effects on asthma. It has been suggested that vitD affects the development and/or severity of asthma by its effects on fetal lung development [5], immune system regulation by its effects on Th1 and Th2 cells and maintaining Treg cell counts and functions [6, 7], direct induction of innate antimicrobial mechanisms, prevention of respiratory tract infections [8], inhibition of remodeling [9], and reducing steroid resistance [10].

The results of the studies are controversial. While some studies have shown that higher $25(\mathrm{OH}) \mathrm{D}$ levels were associated with a reduced risk of any hospitalization, and reduced use of anti-inflammatory medications in the previous year, and lower levels of serum total IgE and eosinophil count [11-13], other studies reported no significant associations [14, 15].

The effect of vitD on the adaptive immune system is important for its relation with asthma. Vitamin D changes the immune system from a proinflammatory to a more tolerogenic immune status. It changes Thelper (Th) cell proliferation and differentiation and modulates their cytokine production. It inhibits the secretion of proinflammatory Th1 (IL-2, interferon- $\gamma$, tumor necrosis factor $\alpha$ ), Th9 (IL-9), Th22 (IL-22) and Th17 cytokines [16, 17]. Th2 cells play a central role in the pathogenesis of asthma. The effects of vitD on Th2 responses are more complex. The literature includes reports of both the inhibition and enhancement of Th2 responses and levels of cytokines such as IL-4, IL-5 and IL-13 [18, 19]. Treg cells are critical for maintaining the immune tolerance. Vitamin $D$ acts directly on T cells to promote Foxp3+ and IL-10+ Tregs and secretion of the immunomodulatory cytokines IL-10 and transforming growth factor- $\beta$ (TGF- $\beta$ ) [20, 21].

\section{Aim}

The aim of the current prospective study is to investigate the relationship between vitD levels and clinical and laboratory parameters of asthma control and atopy and to evaluate the effect of vitD on the adaptive immune response through cytokines and absolute Treg counts simultaneously measured in each season throughout 1 year in Turkish children with asthma.

\section{Material and methods}

Asthmatic patients aged 7 to 17 years, admitted to Mersin University, School of Medicine, Pediatric Allergy and Clinic Immunology Department between November 2011 and February 2012 were included. All patients were diagnosed and classified according to the GINA guidelines [1]. Patients who were sensitized only to house dust mites and who had intermittent or mild persistent asthma severity for the last 3 months were recruited. Patients with chronic lung diseases other than asthma, with diseases that affect the vitD levels (liver or kidney disease, malabsorption), and who use vitD containing drugs or drugs affecting the vitD level (systemic steroids, antiepileptic drugs) were excluded. Written and oral consent from the patients and parents of each patient were obtained, and the study was approved by the local ethical committee of Mersin University.

Study patients were followed up for 1 year. The patients were evaluated at 3-month intervals, once in each season, by questionnaire, lung function tests (LFTs) and blood samples performed simultaneously. Asthma control test (ACT) scores were recorded according to the previous month's asthmatic status. A comprehensive questionnaire about demographic data, medications taken for asthma, and factors affecting vitD level (daily exposure to sun and the amount of dietary vitD per day) was completed at each visit. The duration of daily exposure to the sun was grouped as less than $1 \mathrm{~h} /$ day, 1-3 h/day, and more than $3 \mathrm{~h}$ /day on most days in the previous month. The parents kept food logs, and the amount of dietary vitD was based only on food intake. Vitamin D content of nutrients was defined according to the literature [22]. Body mass index (BMI) was calculated as weight in kilograms divided by the height in squared meters, and recorded at each three-month interval.

Spirometry, bronchodilator response and methacholine provocation tests were conducted in accordance with ATS/ERS recommendations, with a MasterScreen Spirometry System (JaegerCO, Wurzburg, Germany). To calculate the bronchodilator response, the difference between the absolute values of forced expiratory volume in $1 \mathrm{~s}\left(\mathrm{FEV}_{1} \%\right)$ obtained before and after $200 \mu \mathrm{g}$ salbutamol inhalation was divided by the absolute value before salbutamol, and the result was multiplied by 100 . The methacholine provocation test was performed by 2-minute tidal inhalation technique. The test was terminated at the concentration that caused a 20\% decrease in FEV value (provocative concentration (PC20)), or when the $16 \mathrm{mg} / \mathrm{ml}$ concentration was reached without a reaction.

Peripheral venous blood was drawn once in each season simultaneously with pulmonary function tests, for allergic markers (absolute eosinophil count, total IgE level), 25(OH)D level, VDBP, cytokine levels and regulatory $T$ lymphocytes (Treg). All blood was drawn at the same time in the morning, i.e. at 9 a.m., after an 8-hour fasting period, to control for any differences between the participants.

Eosinophil count was analyzed by the flow cytometry method (Sysmex XT 2000i). Total IgE level was analyzed by the nephelometric method (BNProSpec machine, Siemens). Serum 25(OH)D levels were analyzed by high performance liquid chromatography system tandem mass spectrometry (HPLC, Chromsystems-Agilent 1100 device), 
and serum VDBP level was analyzed by enzyme linked immunosorbent assay (ELISA). The absolute number of CD4+CD25+foxp3+ Treg cells were counted by flow cytometry.

Th1 (IL-12, IFN- $\gamma$, IL-2), Th2 (IL-4, IL-13) and Treg (TGF- $\beta$, IL-10) cell cytokines were analyzed in peripheral blood by enzyme linked immunosorbent assay (ELISA) (DSX System, Siemens, USA).

Serum 25(OH)D levels $\leq 20 \mathrm{ng} / \mathrm{ml}$ were considered as vitD deficiency, levels between 20 and $30 \mathrm{ng} / \mathrm{ml}$ were considered as vitD insufficiency, and levels $\geq 30 \mathrm{ng} / \mathrm{ml}$ were considered as sufficient [3].

\section{Statistical analysis}

Data were analyzed using the Statistical Package for Social Sciences for Windows 16.0 (SPSS, Chicago, IL, USA) software. Results were given as either mean \pm standard deviation (SD), or as median \pm interquartile range according to the distribution. ANOVA and Kruskal-Wallis tests were used for the comparison of variables. All the data obtained from all seasons were pooled and correlation tests were used for the correlation analyses of these pooled data. Linear regression models were used for the analysis of the associations of vitD and other parameters. Bonferroni corrections were applied for multiple comparisons. $P$-values $<0.05$ were considered as significant.

\section{Results}

The mean age of the asthmatic patients was 11.74 \pm 2.4 years. Ten $(33.3 \%)$ were female. Fifteen asthmatic patients were on low-dose inhaled corticosteroid (ICS) therapy. Patients on ICS treatment did not differ significantly for any sociodemographic and clinical variable from patients not on ICS treatment (data not shown).

The seasonal distribution of serum vitD and VDBP levels, ACT scores, lung function tests, eosinophil counts, total lgE and cytokine levels of asthmatic patients are shown in Table 1. There were significant differences of vitD levels between spring and summer $(p=0.02)$, summer and winter $(p=0.002)$, and autumn and winter $(p=0.01)$. Seasonal distribution of vitD levels, ACT scores, VDBP levels and $\mathrm{FEV}_{1} \%$ values were presented in Figure 1.

The levels of vitD, VDBP, ACT score and $\mathrm{FEV}_{1} \%$ value presented a trend where these parameters were the lowest in winter and highest in summer.

Mean percent bronchodilator response and PC20 values were not statistically significantly different between the seasons.

The mean total IgE levels and absolute eosinophil counts were lowest in summer and highest in winter and differences were significant for both of these parameters between these seasons. Absolute Treg count was the highest in summer, and it was significantly different from spring and autumn. Only IL-4 level was significantly different between all the seasons except for between summer and autumn among the cytokines, and its level was highest in winter. IL-12 level was different between all the seasons except for between spring and summer. No significant differences were found for IL-13, IL-2 and IFN- $\gamma$ levels between the seasons. IL-10 and TGF- $\beta$ levels were significantly different between winter and the other seasons except for the former's nonsignificant result between winter and spring.

Table 1. Distribution of vitD, VDBP, ACT score, total lgE level, absolute Treg and absolute eosinophil count and cytokine levels

\begin{tabular}{|c|c|c|c|c|c|}
\hline Parameter & Winter & Spring & Summer & Autumn & $P$-value \\
\hline VitD [ng/ml] & $21.36 \pm 8.68$ & $24.46 \pm 8.81$ & $30.7 \pm 9.89$ & $26.43 \pm 6.19$ & 0.001 \\
\hline VDBP [mg/dl] & $20.0 \pm 16.01$ & $46.59 \pm 12.2$ & $51.84 \pm 5.09$ & $47.56 \pm 7.99$ & $<0.001$ \\
\hline ACT score & $19.3 \pm 2.41$ & $23 \pm 2.95$ & $24.5 \pm 1.95$ & $22 \pm 1.82$ & $<0.001$ \\
\hline Total lgE* [IU/m] & $722.7 \pm 688.5$ & $591.3 \pm 490.5$ & $450.30 \pm 162.6$ & $662.83 \pm 234.6$ & 0.031 \\
\hline 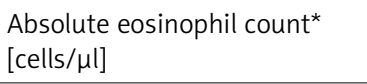 & $553.3 \pm 273.1$ & $451.7 \pm 205.8$ & $372.9 \pm 158.3$ & $459.8 \pm 197.4$ & 0.015 \\
\hline Absolute Treg count $[\text { cells } / \mu l]^{*}$ & $52.88 \pm 45.77$ & $33.71 \pm 27.09$ & $82.36 \pm 61.56$ & $41.31 \pm 38.13$ & $<0.001$ \\
\hline $\mathrm{IL}-4[\mathrm{pg} / \mathrm{ml}]^{\star \star}$ & $14.2(11.5-25.7)$ & $3.7(2.23-7.36)$ & $2.69(2.05-6.41)$ & $2.06(1.6-4.58)$ & $<0.001$ \\
\hline $\mathrm{IL}-10[\mathrm{pg} / \mathrm{ml}]^{\star \star}$ & $6.9(2.15-15.62)$ & $5.7(4.54-7.68)$ & $4.8(3.94-6.78)$ & $4.6(3.79-12.60)$ & $<0.001$ \\
\hline $\mathrm{IL}-13[\mathrm{pg} / \mathrm{ml}]^{\star *}$ & $2.3(0.019-48.76)$ & $0.6(0.019-23.67)$ & $0.8(0.004-24.6)$ & $0.7(0.034-23.33)$ & 0.0635 \\
\hline TGF- $\beta[\mathrm{ng} / \mathrm{ml}]^{\star \star}$ & $2.4(0.019-35.9)$ & $0.05(0.02-1.19)$ & $0.03(0.008-1.14)$ & $0.05(0.021-1.67)$ & $<0.001$ \\
\hline $\mathrm{IFN}-\gamma[\mathrm{IU} / \mathrm{ml}]^{\star \star}$ & $0.07(0.028-0.38)$ & $0.08(0.033-0.36)$ & $0.06(0.029-0.30)$ & $0.08(0.021-0.269)$ & 0.125 \\
\hline IL-12p40 [pg/ml $]^{\star *}$ & $86.2(18.84-524.6)$ & 190.7 (35.4-488.4) & $186.8(52.5-735.2)$ & 316.8 (78.2-1194.4) & $<0.001$ \\
\hline $\mathrm{IL}-2[\mathrm{IU} / \mathrm{ml}]^{\star \star}$ & $0.8(0.626-3.96)$ & $1.0(0.86-1.08)$ & $0.9(0.81-1.07)$ & $1.0(0.78-1.85)$ & 0.345 \\
\hline
\end{tabular}

*Mean \pm SD, **median (minimum-maximum). 

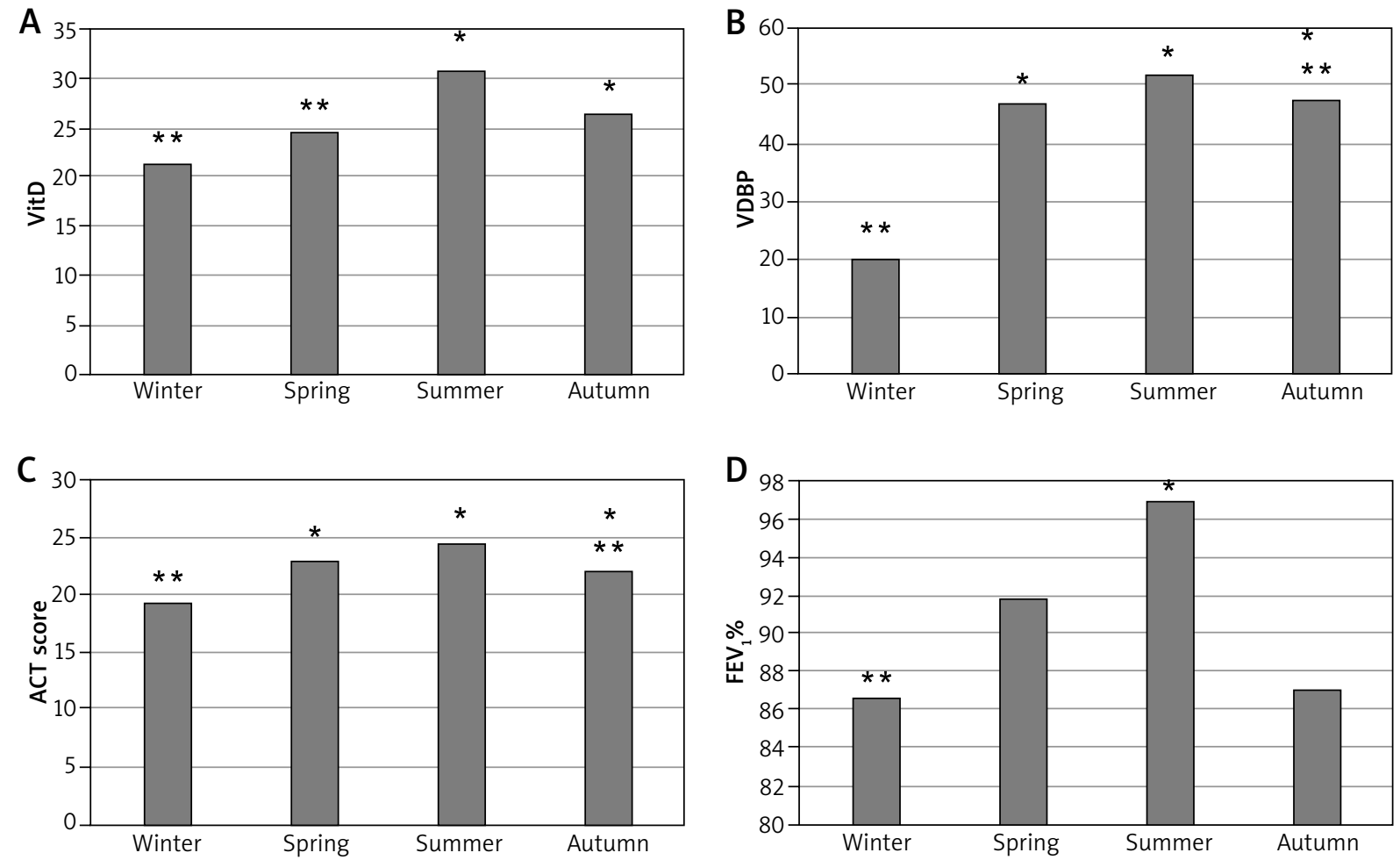

*Significantly different from winter, ** significantly different from summer.

Figure 1. Seasonal distribution of vitD (A) and VDBP (B) levels, ACT score (C) and FEV ${ }_{1} \%$ value (D)

Table 2. Correlations between pooled vitamin D levels and clinical and laboratory parameters

\begin{tabular}{|c|c|c|}
\hline Parameter & $\begin{array}{l}\text { Correlation } \\
\text { coefficient }(r)\end{array}$ & $P$-value \\
\hline ACT score & 0.498 & $<0.001$ \\
\hline $\begin{array}{l}\text { Daily dietary vitamin D } \\
\text { [ } \mu \mathrm{g} / \text { day] }\end{array}$ & 0.134 & 0.043 \\
\hline $\operatorname{VDBP}[\mathrm{mg} / \mathrm{dl}]$ & 0.377 & 0.043 \\
\hline $\begin{array}{l}\text { Absolute eosinophil count } \\
\text { [cells/ } \mu l]\end{array}$ & 0.009 & 0.923 \\
\hline Total IgE [IU/ml] & -0.532 & 0.041 \\
\hline 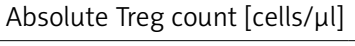 & 0.403 & 0.034 \\
\hline IL-2 [IU/ml] & -0.226 & 0.072 \\
\hline IL-4 [pg/ml] & -0.293 & 0.001 \\
\hline IL-10 [pg/ml] & -0.099 & 0.283 \\
\hline IL-12 [pg/ml] & 0.151 & 0.099 \\
\hline IL-13 [pg/ml] & 0.128 & 0.164 \\
\hline TGF- $\beta[\mathrm{ng} / \mathrm{ml}])$ & -0.170 & 0.064 \\
\hline $\mathrm{IFN}-\gamma[\mathrm{IU} / \mathrm{ml}]$ & -0.195 & 0.064 \\
\hline $\mathrm{FEV}_{1} \%$ & 0.483 & 0.031 \\
\hline Bronchodilator response (\%) & -0.468 & 0.038 \\
\hline PC20 [mg/ml] & 0.346 & 0.453 \\
\hline
\end{tabular}

A correlation analysis between pooled vitD levels and other parameters was performed. Serum vitD level was significantly and positively correlated with dietary vitD intake level, ACT scores, VDBP levels, absolute Treg values, and $\mathrm{FEV}_{1} \%$ values, and negatively correlated with total IgE levels, bronchodilator response and IL-4 level. There were no significant correlations between vitD lev-

Table 3. Multivariate regression analysis of the association between vitamin $\mathrm{D}$ level and clinical and laboratory parameters

\begin{tabular}{lcc}
\hline Parameter & $\beta(95 \% \mathrm{Cl})$ & $P$-value \\
\hline ACT score & $0.47(0.31-0.63)$ & 0.023 \\
\hline FEV $_{1}(\%)$ & $0.52(0.40-0.72)$ & 0.041 \\
\hline $\begin{array}{l}\text { Bronchodilator response } \\
(\%)\end{array}$ & $-0.56(-0.64--0.25)$ & 0.034 \\
\hline Total lgE [IU/ml] & $-0.61(-0.74--0.24)$ & 0.006 \\
\hline PC20 [mg/ml] & $0.28(0.12-0.32)$ & 0.07 \\
\hline $\begin{array}{l}\text { Absolute Treg count } \\
\text { [cells/ } \mu \mathrm{l}]\end{array}$ & $0.41(0.23-0.50)$ & 0.14 \\
\hline IL-4 [pg/ml] & $-0.10(-0.80-0.46)$ & 0.604 \\
\hline
\end{tabular}

Multivariate models were adjusted by age, BMI, ICS use, daily sun exposure, VDBP level and season. 
els and eosinophil counts and cytokine levels other than IL-4 (Table 2).

A multivariate regression analysis of the relation between pooled vitD levels and pooled ACT score, allergic markers, Treg level, IL-4 level, spirometric parameters, bronchodilator response, and PC20 values was performed by multivariate regression analyses by taking into account the confounding factors (age, BMI, ICS use, daily sun exposure, VDBP level and season). Vitamin D levels were significantly and positively associated with ACT scores and $\mathrm{FEV}_{1} \%$ values, and negatively associated with bronchodilator response and total lgE levels. A $1 \mathrm{ng} / \mathrm{ml}$ increase of vitD level was associated with a 0.47 point increase in the ACT score, a $0.52 \%$ increase in $\mathrm{FEV}_{1} \%$ value, a $0.56 \%$ decrease in bronchodilator response, and a 0.61 $\mathrm{IU} / \mathrm{ml}$ decrease in total IgE level (Table 3). The association between vitD and Treg and IL-4 levels became nonsignificant after adjustment.

\section{Discussion}

The present prospective study revealed that serum vitD deficiency was significantly associated with worse asthma control and LFTs, independent from duration of sun exposure, season, ICS use and BMI, and serum vitD level was positively correlated with absolute Treg values, and negatively correlated with IL-4 level throughout 1-year follow-up.

There are many studies about the effects of vitD on asthma. Beneficial effects of vitD on asthma such as antiviral effects, suppression of inflammation, an increase in the number and function of Tregs, augmentation of the response to steroids, and inhibition of remodeling were demonstrated [5]. However, the evidence remains conflicting with other studies reporting negative effects as well as an absence of any effect of vitD on asthma [13, 23, 24]. The major limitation of most of these studies is their crosssectional design. It is difficult to ascertain from cross-sectional studies whether vitD deficiency is responsible for reduced asthma control, or whether uncontrolled asthma is associated with lifestyle, such as less outdoor exercise with decreased exposure to sunlight, thereby being responsible for lower serum levels of vitD. Although there are some vitD intervention studies, it is also important to evaluate the natural seasonal changes, and associations of these changes with asthma. For these reasons, we evaluated vitD levels of the asthmatic patients throughout 1 year. Also, we pooled the data of asthmatic patients obtained from different seasons and time points in order to partially eliminate the reverse causation effect.

Similar to the results of some studies in the literature $[25,26]$, our correlation analysis showed that serum vitD levels were positively correlated with ACT scores, absolute Treg counts, and $\mathrm{FEV}_{1} \%$ predicted values, and negatively correlated with serum total IgE levels, bronchodilator response and serum IL-4 level.
The confounders that effect asthma control and allergic markers other than vitD should be taken into account to obtain more reliable results to investigate the association of asthma and vitD. According to some studies with this design, a decrease in vitD level is associated with an increased number of hospitalizations and emergency department visits [11-13, 27], the risk of severe asthma attacks [27], bronchodilator response and bronchial hyperreactivity [13], total IgE levels and eosinophil count [13], and decreased ACT scores [12]. Also there are studies that found no associations between vitD and emergency department visits, hospitalizations [15], FEV values [11, 14], IgE levels [14] and eosinophil count [15]. As sunlight exposure may decrease with increasing asthma severity as a result of an inactive lifestyle, we added the duration of sunlight exposure as a confounder in multivariate analysis. Also season likely affects asthma severity through pathways independent from vitD, so we added season as a confounder, as well. As a result of our multivariate analysis we found that each $1 \mathrm{ng} / \mathrm{ml}$ decrease in vitD level was associated with a 0.47 point decrease in ACT score, a $0.52 \%$ decrease in $\mathrm{FEV}_{1} \%$ value, a $0.56 \%$ increase in bronchodilator response, and a $0.61 \mathrm{lU} / \mathrm{ml}$ increase in total IgE level, which pointed to an independent association between serum vitD levels and asthma control. Our prospective pooled data analyses may have obtained more reliable results compared with the previous cross-sectional or one-sample studies in the literature.

The effect of vitD on the adaptive immune system is an important mechanism hypothesized to be responsible for the relationship between vitD and asthma. There are few studies in the literature that evaluated the relationship of T cells and their cytokines and vitamin D in asthmatic patients. Two different studies, one of which used BAL samples, while the other used blood samples, showed that vitD levels of asthmatic patients were positively correlated with Treg cell counts [28, 29]. There is limited information on the variations of the adaptive immune response of individuals in response to physiological changes in vitD during the different seasons of the year. To the best of our knowledge, there is only one study in the literature that analyzed the relationship between seasonal changes of vitD and T cell responses in vivo, which showed that the seasonal increase of vitD was not associated with a significant change in absolute Treg count but was associated with an increase in Foxp3 expression of Treg cells and decreases in Th1 (IFN- $\gamma$, IL-2) and Th17 (IL-17) cytokines [30]. In the present study we evaluated cytokines of Th1, Th2 and Treg cells simultaneously and we found that IL-4 (Th2 type cytokine) level is highest in winter and its level is significantly different from summer, and there is a negative correlation between vitD and IL-4 levels throughout the seasons. Because we only recruited house dust mite allergic patients and since exposure to this allergen occurs throughout the year, we hypothesized that higher levels of IL-4 in winter may not 
be associated with the exposure to the allergen but instead may be due to vitD deficiency in winter. Although there is a significant positive correlation between vitD and Treg cell count and although absolute Treg cell count is highest in summer, the highest Treg cell cytokine levels were obtained in winter. The association of Treg cell counts and IL4 levels with vitD levels, however, was no longer significant after controlling for confounders. Further, we could not find any association between vitD levels and Th1 type cytokines. A possible explanation for this may be that the serum levels of cytokines may not adequately represent the airway mucosal levels and associations of Treg cells and other cytokines and vitD. Another explanation might be that cytokine levels were measured by ELISA, not after stimulation of peripheral mononuclear cells.

In the study by Brehm et al., which included 616 asthmatic children, it was found that vitD deficiency was associated with increased bronchial hyperreactivity [13]. However, in another study including 1024 children by the same investigator this association could not be demonstrated [27]. Also in the study by Bar et al. it was shown that 6 weeks of vitD supplementation had no significant effect on PC20 values in 36 mild asthmatic children [24]. Although we found a significant association between vitD and bronchodilator response, we did not observe a significant relation with PC20. In our study although ICS use was taken as a confounder, a high rate of ICS use may have affected the results. Also the low number of participants and mild severity level of all asthmatics may have changed the relation between vitD and PC20 values. In addition, the methacholine provocation test reflects both the inflammatory and remodeling components of airways [31]. Hence it may not be an optimal way of analyzing vitD effects on inflammatory components of bronchial hyperreactivity. Indirect provocation tests such as adenosine or exercise might have better reflected this association.

In vitro immunomodulatory effects of VDBP such as to augment the chemotaxis functions of monocytes and neutrophils, and to stimulate macrophages to shift to the phagocytic phenotype, have been observed in some studies [32]. There are only a few in vivo studies evaluating the relationship between the level of VDBP and asthma. In a short communication paper, the authors identified that BAL VDBP levels were inversely correlated with asthma severity, as assessed by the ACT, spirometry and ICS usage [33]. Thus VDBP may affect inflammation and asthma control. Therefore VDBP levels were entered as confounders at the first step of the regression analysis. In our study we also found that serum vitD level was significantly and positively correlated with VDBP levels in the pooled dataset.

A strength of our study is the elimination of possible reverse causation by obtaining and analyzing multiple seasonal data from every asthmatic patient by its prospective design. Another strength is the evaluation of multiple parameters of asthma via inflammatory markers and cytokines.

A limitation of our study is its relatively small sample size. The evaluation of the cytokine levels and Treg cell counts from the peripheral blood, and not from the local tissues, is another limitation.

\section{Conclusions}

Our study added to the few prospective studies investigating serum vitD levels, among asthmatics in each season. This study revealed that serum vitD levels significantly affected asthma control measures, LFTs and IgE levels independent from age, BMI, ICS use and daily sun exposure and season. Therefore serum vitD levels should be regularly, even in summer, evaluated in asthmatic children, and possibly supplemented if necessary, in order to control asthma optimally. This study is important because it revealed the relationship between vitD and asthma in the context of asthmatic inflammation, and it adds to the relatively small number of studies in the literature.

\section{Conflict of interest}

The authors declare no conflict of interest.

\section{References}

1. Global Strategy for Asthma Management and Prevention. Global Initiative for Asthma (GINA) 2012 update.

2. Wacker M, Holick MF. Vitamin D - effects on skeletal and extraskeletal health and the need for supplementation. Nutrients 2013; 5: 111-48.

3. Vieth R. Why the minimum desirable serum 25-hydroxyvitamin D level should be $75 \mathrm{nmol} / \mathrm{L}(30 \mathrm{ng} / \mathrm{ml})$. Best Pract Res Clin Endocrinol Metabol 2011; 25: 681-91.

4. Chun RF, Peercy BE, Orwoll ES, et al. Vitamin D and DBP: the free hormone hypothesis revisited. I Steroid Biochem Mol Biol 2014; 144: 132-7.

5. Edelson JD, Chan S, Jassal D, et al. Vitamin D stimulates DNA synthesis in alveolar type-II cells. Biochim Biophys Acta 1994; 1221: 159-66.

6. Sloka S, Silva C, Wang J, Yong VW. Predominance of Th2 polarization by vitamin D through a STAT6-dependent mechanism. J Neuroinflammation 2011; 8: 56.

7. Staeva-Vieira TP, Freedman LP. 1,25-dihydroxyvitamin D3 inhibits IFN-gamma and IL-4 levels during in vitro polarization of primary murine CD4+ T cells. J Immunol 2002; 168: 1181-9.

8. Busse WW, Lemanske RF, Gern JE. Role of viral respiratory infections in asthma and asthma exacerbations. Lancet 2010; 376: 826-34.

9. Damera G, Fogle HW, Lim P, et al. Vitamin D inhibits growth of human airway smooth muscle cells through growth factor-induced phosphorylation of retinoblastoma protein and checkpoint kinase 1. Br J Pharmacol 2009; 158: 1429-41.

10. Wu AC, Tantisira K, Li L, et al. Effect of vitamin D and inhaled corticosteroid treatment on lung function in children. Am J Respir Crit Care Med 2012; 186: 508-13.

11. Montero-Arias F, Sedó-Mejía G, Ramos-Esquivel G. Vitamin $D$ insufficiency and asthma severity in adults from Costa Rica. Allergy Asthma Immunol Res 2013; 5: 283-8. 
12. Gupta A, Sjoukes A, Richards D, et al. Relationship between serum vitamin $D$, disease severity, and airway remodeling in children with asthma. Am J Respir Crit Care Med 2011; 184: 1342-9.

13. Brehm JM, Celedón JC, Soto-Quiros ME, et al. Serum vitamin D levels and markers of severity of childhood asthma in Costa Rica. Am J Respir Crit Care Med 2009; 179: 765-71.

14. Checkley W, Robinson CL, Baumann LM, et al. 25-hydroxy vitamin D levels are associated with childhood asthma in a population-based study in Peru. Clin Exp Allergy 2015; 45: 273-82.

15. Alyasin S, Momen T, Kashef S, et al. The relationship between serum 25 hydroxy vitamin D levels and asthma in children. Allergy Asthma Immunol Res 2011; 3: 251-5.

16. Cantorna MT. Mechanisms underlying the effect of vitamin D on the immune system. Proc Nutr Soc 2011; 69: 286-9.

17. Lemire JM, Archer DC, Beck L, et al. Immunosuppressive actions of 1,25-dihydroxyvitamin D3: preferential inhibition of Th1 functions. J Nutr 1995; 125: 1704-8.

18. Boonstra A, Barrat FJ, Crain C, et al. 1alpha,25-dihydroxyvitamin D3 has a direct effect on naive CD4+ T cells to enhance the development of Th2 cells. I Immunol 2001; 167: 4974-80.

19. Staeva-Vieira TP, Freedman LP. 1,25-dihydroxyvitamin D3 inhibits IFN-gamma and IL-4 levels during in vitro polarization of primary murine CD4+ T cells. J Immunol 2002; 168: 1181-9.

20. Ardalan MR, Maljaei H, Shoja MM, et al. Calcitriol in the donor expands the population of CD4+CD25+ T cells in renal transplant recipients. Transplant Proc 2007; 39: 951-3.

21. Chambers ES, Hawrylowicz CM. The impact of vitamin D on regulatory T cells. Curr Allergy Asthma Rep 2011; 11: 29-36.

22. Lamberg-Allardt C. Vitamin D in foods and as supplements. Prog Biophys Mol Biol 2006; 92: 33-8.

23. Rothers J, Wright AL, Stern DA, et al. Cord blood 25-hydroxyvitamin $D$ levels are associated with aeroallergen sensitization in children from Tucson, Arizona. J Allergy Clin Immunol 2011; 128: 1093-109.

24. Bar YR, Livnat G, Schnapp Z, et al. The effect of vitamin D on airway reactivity and inflammation in asthmatic children: a double-blind placebo-controlled trial. Pediatr Pulmonol 2015; 50: 747-53.

25. Chinellato I, Piazza M, Sandri M, et al. Vitamin D serum levels and markers of asthma control in Italian children. J Pediatr 2011; 158: 437-41.

26. Searing DA, Zhang Y, Murphy JR, et al. Decreased serum vitamin D levels in children with asthma are associated with increased corticosteroid usage. J Allergy Clin Immunol 2010; 125: 995-1000.

27. Brehm JM, Schuemann B, Fuhlbrigge AL, et al. Serum vitamin D levels and severe asthma exacerbations in the childhood asthma management program study. J Allergy Clin Immunol 2010; 126: 52-8.

28. Maalmi H, Berraïes A, Tangour E, et al. The impact of vitamin D deficiency on immune $T$ cells in asthmatic children: a case-control study. J Asthma Allergy 2012; 5: 11-9.

29. Urry Z, Chambers ES, Xystrakis E, et al. The role of 1alpha,25dihydroxyvitamin D3 and cytokines in the promotion of distinct Foxp3+and IL-10+ CD4+ T cells. Eur I Immunol 2012; 42: 2697-708.

30. Khoo AL, Koenen HJ, Chai LY, et al. Seasonal variation in vitamin D3 levels is paralleled by changes in the peripheral blood human T cell compartment. PLoS One 2012; 7: e29250.

31. Brusasco V, Crimi E. Methacholine provocation test for diagnosis of allergic respiratory diseases. Allergy 2001; 56 : 1114-20.
32. Yamamoto N, Homma S. Vitamin D3 binding protein (groupspecific component) is a precursor for the macrophage-activating signal factor from lysophosphatidylcholine-treated lymphocytes. Proc Natl Acad Sci USA 1991; 88: 8539-43.

33. Gupta A, Dimeloe S, Richards DF, et al. Vitamin D binding protein and asthma severity in children. J Allergy Clin Immunol 2012; 129: 1669-71. 